\title{
Influence of rainfall spatial resolution on flash flood modelling
}

\author{
M. Sangati and M. Borga \\ Department of Land and Agroforest Environment, University of Padova, Agripolis, Legnaro (PD), Italy \\ Received: 4 April 2008 - Revised: 5 February 2009 - Accepted: 30 March 2009 - Published: 9 April 2009
}

\begin{abstract}
High resolution radar rainfall fields and a distributed hydrologic model are used to evaluate the sensitivity of flash flood simulations to spatial aggregation of rainfall at catchment scales ranging from $10.5 \mathrm{~km}^{2}$ to $623 \mathrm{~km}^{2}$. The case study focuses on the extreme flash flood occurred on 29 August 2003 on the eastern Italian Alps. Four rainfall spatial resolutions are considered, with grid size equal to 1-, $4-, 8-$ and $16-\mathrm{km}$. The influence of rainfall spatial aggregation is examined by using the flow distance as a spatial coordinate, hence emphasising the role of river network in the averaging of space-time rainfall. Effects of rainfall spatial aggregation are quantified by using a dimensionless parameter, represented by the ratio of rainfall resolution $\left(L_{r}\right)$ to the characteristic basin length $\left(L_{w}\right)$, taken as the square root of the watershed area. Increasing the $L_{r} / L_{w}$ parameter induces large errors on the simulated peak discharge, with values of the peak discharge error up to 0.33 for $L_{r} / L_{w}$ equal to 1.0. An important error source related to spatial rainfall aggregation is the rainfall volume error caused by incorrectly smoothing the rainfall volume either inside or outside of of the watershed. It is found that for $L_{r} / L_{w}<1.0$, around $50 \%$ of the peak discharge error is due to the rainfall volume error. Remaining errors are due to both the distortion of the rainfall spatial distribution, measured with respect to the river network, and to the reduced spatial variability of the rainfield. Further investigations are required to isolate and examine the effect of river network geometry on the averaging of spacetime rainfall at various aggregation lengths and on simulated peak discharges.
\end{abstract}

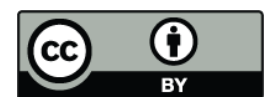

Correspondence to: $\mathrm{M}$. Borga (marco.borga@unipd.it)

\section{Introduction}

Rainfall is the primary input to most hydrological systems, and a key issue for hydrological science and practice is to assess the importance of the spatial structure of rainfall and its representation for flood runoff generation. This problem is particularly important for the case of flash flood events, which are characterised by high space-time variability both in the rainfall forcing and in the hydrologic response (Creutin and Borga, 2003). The influence of rainfall representation on the modelling of the hydrologic response is expected to depend on complex interactions between the rainfall space-time variability, the variability of the catchment soil and landscape properties, and the spatial scale (i.e. catchment area) of the problem (Obled et al., 1994; Woods and Sivapalan, 1999; Bell and Moore, 2000; Smith et al., 2004). The literature addressing this problem includes quite heterogeneous approaches in terms of the methodologies adopted and conclusions drawn from the analyses (Nicotina et al., 2008).

In general, when addressing the problem of the sampling scale effect, it is found that the measured (apparent) variability of spatially-continuous fields depends on two terms: extent and support (Blöschl and Sivapalan, 1995). "Extent" refers to the overall coverage of the data (the watershed scale, given by $L_{w}$, root square of the watershed area); "support" refers to the resolution area (the aggregation length, $L_{r}$ ). Based on theoretical and empirical evidence, it is found that the apparent spatial variability of the rainfall field represented at some aggregation scale decreases with decreasing the "extent" and with increasing the aggregation length. The first effect is a logical consequence of the existence of spatial correlations: for a given aggregation length, the smaller $L_{w}$, the closer the data and, thus, the closer their values. The second effect arises because dispersion within a fixed domain $L_{w}$ decreases as the support $L_{r}$ increases: the rainfall values at $8-\mathrm{km}$ resolution are less dispersed than the rainfall values at $1-\mathrm{km}$ resolution, for a fixed domain.

Published by Copernicus Publications on behalf of the European Geosciences Union. 


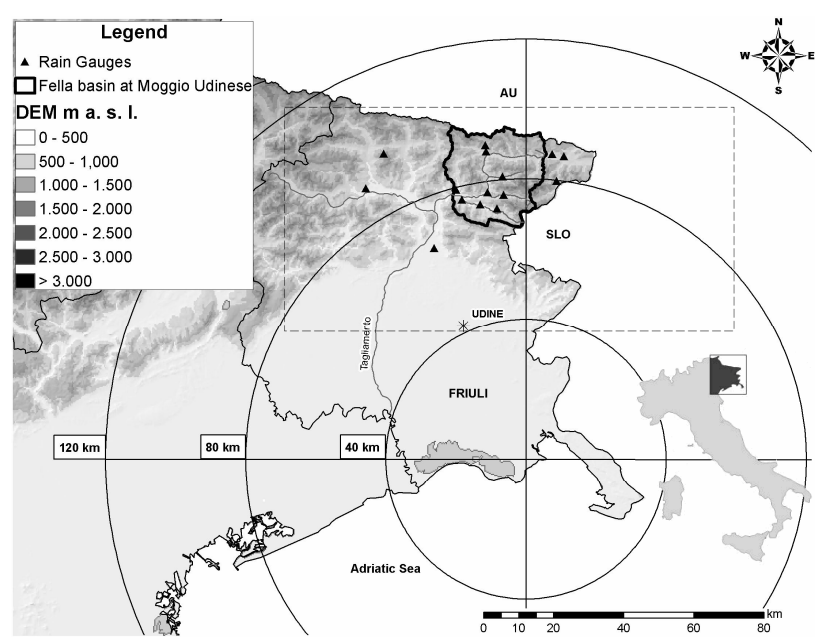

Fig. 1. Location of the OSMER radar and the Fella river basin at Moggio Udinese with topography of North-eastern Italy. The locations of the raingauge stations used in the study are also reported. The dotted line rectangle represents the area used for the analyses of rainfall spatial variability reported in Fig. 3.

Increasing the aggregation length leads not only to a reduction of the rainfall apparent spatial variability. It has been found (Ogden and Julien, 1994; Winchell et al., 1998; Segond et al., 2007) that when the ratio $L_{r} / L_{w}$ exceeds a certain threshold, the uncertainty in the location of precipitation over the catchment becomes a major source of error in rainfall volume estimation at the catchment scale. Indeed, typical spatially varying rainfall patterns consist of regions of heavier or lighter precipitation outside the immediate boundaries of a catchment. Rainfall values pertaining to areas just outside the catchment may enter the computation of the average rainfall over the basin by increasing the resolution area. As such, this error source leads to a rainfall volume error.

The sensitivity of runoff modelling to both attenuated spatial variability and rainfall volume error depends strongly on the smoothing effect of catchment characteristics (Winchell et al., 1998; Segond et al., 2007). When there is not enough variability in rainfall to overcome the damping effect of the catchment, detailed knowledge of rainfall spatial variability is not required to model the catchment response, although reliable information of catchment-averaged rainfall is important (Naden, 1992; Obled et al., 1994; Woods and Sivapalan, 1999; Smith et al., 2004; Andreassian et al., 2001). However, there is not an agreed approach to quantify the damping effect of a given catchment and the conclusions drawn from the different studies depend heavily on the runoff model, the characteristics of the rainfall forcing and the type of catchment examined.

Focusing the analysis on flash flood events allows one to isolate specific runoff generation mechanisms and catchment properties which are perceived as dominant with this type of events. In particular, the substantial role exerted by Hor- tonian runoff generation with high intensity rainfall events emphasise the role of surface runoff and river network geometry in the averaging of space-time rainfall (Norbiato et al., 2008). In this case, the concept of flow distance, i.e. the distance along the runoff flow path from a given point to the outlet, may provide a useful metric to examine the influence of rainfall resolution on runoff modelling (Woods and Sivapalan, 1999). The dampening effect arises here because the excess rainfall generated at points placed at equal flow distance will be averaged out in the runoff propagation process, in spite of the rainfall spatial variability. The averaging of space-time rainfall fields across locations with equal flow distance coordinates may be sensitive to the spatial resolution of the rainfall representation and as such it may explain, at least partially, the pattern of runoff model sensitivity to rainfall resolution.

These concepts are examined in this study with reference to the flash flood event which occurred on 29 August 2003 in the Fella river basin (eastern Italian Alps). The regional flood response of the Fella river basin is examined in terms of space-time rainfall variability and heterogeneous land surface properties. A distributed hydrologic model, which includes an empirical infiltration model and a network-based representation of hillslope and channel response, plays a central role in examining the regional flood response. Detailed observations from a weather radar are used to estimate the rainfall forcing (Borga et al., 2007). To elucidate the controls of rainfall spatial aggregation on model error, the distributed hydrologic model is applied over ten different sub basins ranging from $10.5 \mathrm{~km}^{2}$ to $623.0 \mathrm{~km}^{2}$ and by using four different rainfall resolutions: 1-, 4-, 8- and 16-km. The range of spatial resolution covers the aggregation scales often encountered in flash flood forecasting, from fine-scale radar rainfall estimates to large-scale rainfall forecasts provided by numerical weather forecast models.

The paper is organized as follows. Section 2 describes the study region and provides the documentation of the flash flood event used in this investigation. Section 3 illustrates the distributed model used in the study, whereas Sect. 4 examines its sensitivity to spatial resolution of rainfall over a range of catchment scales. Section 5 completes the paper with discussion and conclusions.

\section{The Fella 2003 flash flood}

The flash flood of the Fella catchment on 29 August 2003 (Fig. 1) occurred at the end of a climatic anomaly of a dry and hot summer and was one of the most devastating flash flood events in North-Eastern Italy since starting of systematic observations. The rainfall event started at 10:00 CET (Central European Time) and lasted for $12 \mathrm{~h}$, focusing on the $705 \mathrm{~km}^{2}$-wide Fella basin (Fig. 2), which is a major left-hand tributary of the Tagliamento river system. The Fella basin has a mean altitude of $1140 \mathrm{~m}$ a.s.l., with an average annual 
precipitation of $1920 \mathrm{~mm}$. Ten subbasins of the Fella river system are examined in this study, ranging from $10.5 \mathrm{~km}^{2}$ to $623 \mathrm{~km}^{2}$.

Extreme rainfall from the August 2003 storm was produced by quasi-stationary convective banded structures. Some of the bands persisted in the same locations for the duration of the event. The steadiness of these rainbands led to highly variable precipitation accumulations and runoff (Borga et al., 2007). The storm total precipitation (Fig. 2) is characterised by a band of rainfall accumulation exceeding $300 \mathrm{~mm}$ localised on the right-hand tributaries of the Fella river. The storm total rainfall distribution reflects south west - north east motion of the storm elements and westeast shift of the tracks of the storms. Rainfall intensity up to $100 \mathrm{~mm} \mathrm{~h}^{-1}$ over 15 -min time step was recorded during the explosive growth phase of the storm (between 14:00 and 18:00 CET) (Norbiato et al., 2007). Rainfall produced by the August 2003 storm resulted in severe flooding throughout the Fella river basin. The storm produced catastrophic flooding at drainage areas up to $80-90 \mathrm{~km}^{2}$.

\subsection{Post event field campaign}

Flash flood events are difficult to monitor because they develop at space and time scales that conventional measurement networks of rain and river discharges are not able to sample effectively (Borga et al., 2008). This explains why the investigation of flash flood events is by necessity eventbased and opportunistic as opposed to driven by observations from carefully designed field campaigns. Post-event surveys play therefore a critical role in gathering essential observations to implement and verify hydrological models for flash flood analyses.

Following the August 2003 event, post flood surveys were planned. Surveys were concentrated in the upper Fella basin and included: (i) collection of rainfall data, (ii) collection of streamgauge data and execution of indirect peak flood estimation, and (iii) postflood interviews.

Radar and raingauge observations were used to derive rainfall fields for the August 2003 storm. 5-min raingauge data were collected at 15 raingauges (Fig. 1), whereas storm total rainfall was available at further six daily raingauges. Volume scan reflectivity data from the Doppler, dual-polarised C-band OSMER radar station, located at Fossalon di Grado (Fig. 1) (time resolution of $5 \mathrm{~min}$ and spatial resolution of $250 \mathrm{~m}$ in range by 0.9 degree in azimuth), were used to derive radar rainfall rates. Spatially detailed rainfall estimates were obtained by adjusting radar observation accounting for the physics of the radar sensing and incorporating accumulated values of the available raingauge stations (Borga et al., 2002).

Streamgauge data and observations from post-event surveys, combined with hydraulic modelling, were used to examine the hydrologic response to the storm. Stream gauge data were available at eight sites, generally located either

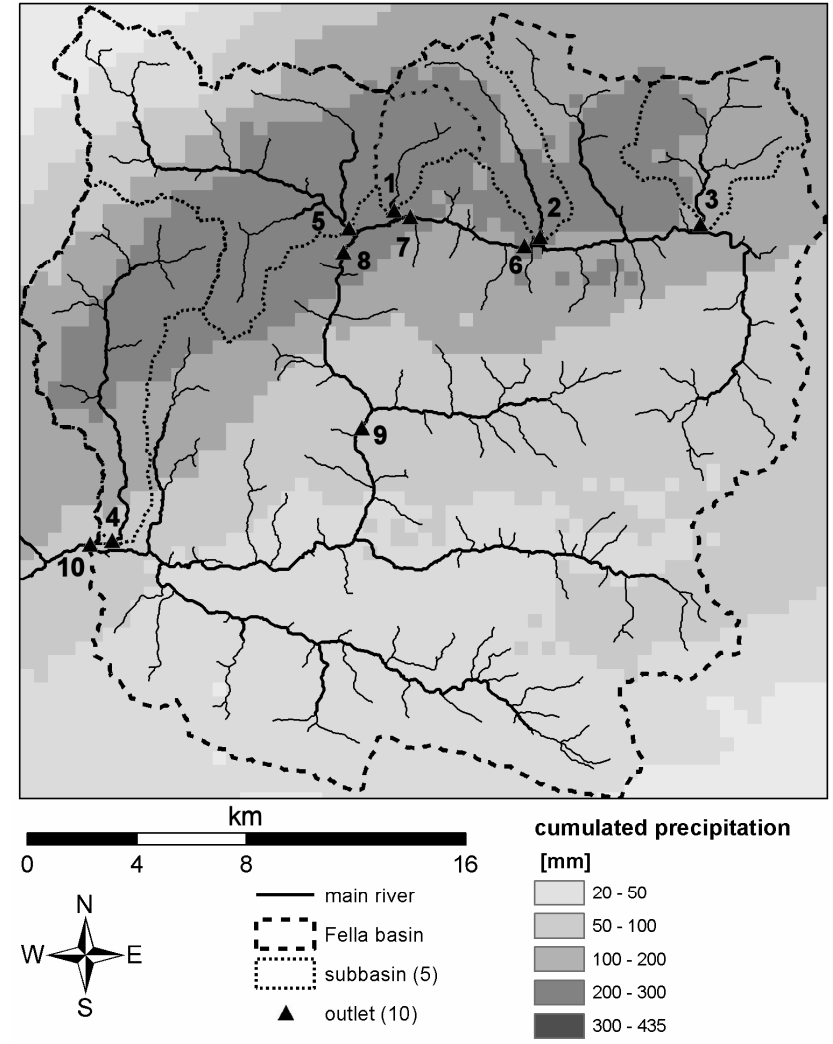

Fig. 2. Storm total rainfall (mm) for the 29 August 2003 storm on the Fella river basin at Moggio (basin outlet $10,623 \mathrm{~km}^{2}$ ) with the nine study subbasins: Rio degli Uccelli at Pontebba $\left(1,10.5 \mathrm{~km}^{2}\right)$; Rio Bianco at S. Caterina $\left(2,17.5 \mathrm{~km}^{2}\right)$; Uque at Ugovizza (3, $\left.24 \mathrm{~km}^{2}\right)$; Aupa at Moggio Udinese $\left(4,50 \mathrm{~km}^{2}\right)$; Pontebbana at Pontebba $\left(5,71.2 \mathrm{~km}^{2}\right)$; Fella at S. Caterina $\left(6,139 \mathrm{~km}^{2}\right)$; Fella at Pontebba $\left(7,165 \mathrm{~km}^{2}\right)$; Fella at S. Rocco $\left(8,250 \mathrm{~km}^{2}\right)$ and Fella at Dogna $\left(9,329 \mathrm{~km}^{2}\right)$.

close or at bridge crossing sites, where measurements are taken by means of ultrasound sensors. Hydraulic modelling, combined with surveys of the post-flood river section geometry and data about pre- and post-flood geometry, was used to derive stage-discharge relationships at these river sections (Borga et al., 2007). Furthermore, hydraulic modelling was used to estimate peak discharges based on surveyed high watermarks and postflood channel geometry at another three sites (including the site at the outlet of Uqua basin, Fig. 2) and to confirm the estimates at the gauged sections. Twentytwo local residents, mostly located close to the Uqua river basin and its fan, were interviewed about the severity of the storm, occurrences of surface flow, timing of rainfall and stage peaks.

\subsection{Precipitation analyses}

The structure of the rainfall spatial variability has been examined by using the climatological variogram (Lebel et al., 
a)

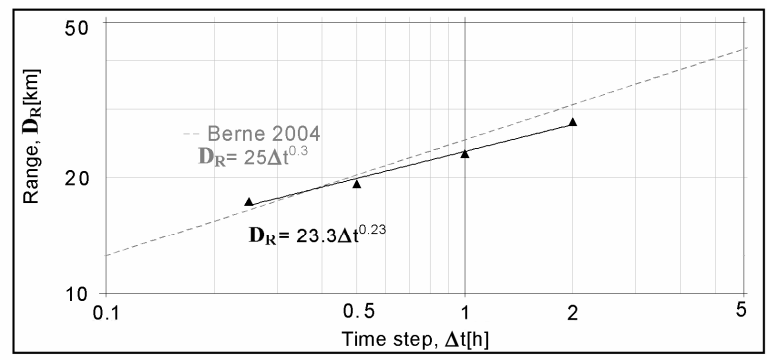

b)

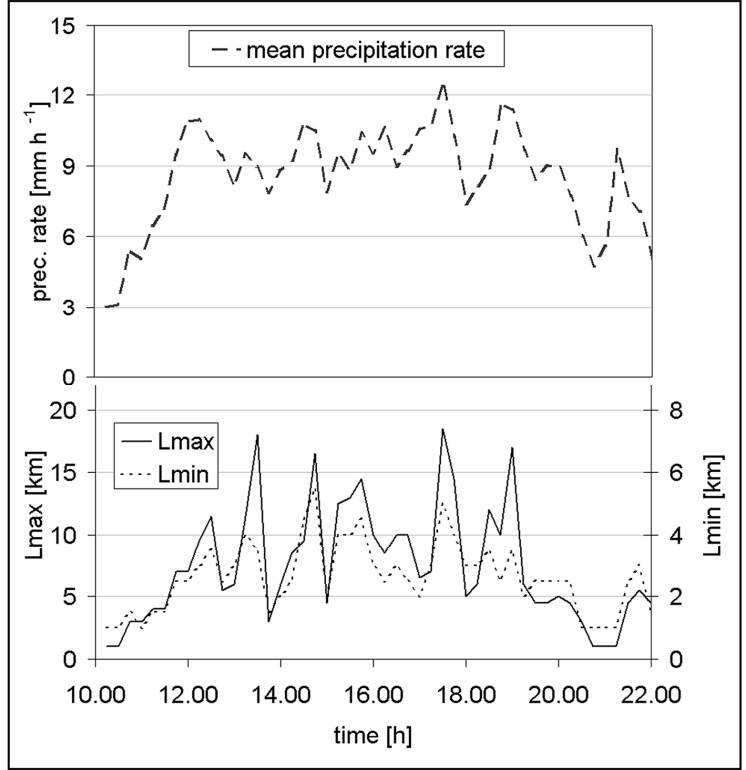

Fig. 3. Rainfall spatial variability analysis:

(a) Range $[\mathrm{km}]$, resulting from spatial climatological variogram analysis, versus time step [h]; results are compared with analysis carried out by Berne et al. (2004) (dashed line);

(b) Mean precipitation of non zero values inside the rectangle area shown in Fig. 1.

(c) Lengths of maximum and minimum axis for indicator variogram on binary rainfall fields using $20 \mathrm{~mm} \mathrm{~h}^{-1}$ threshold.

1987; Berne et al., 2004). The domain used for this analyses is a $128 \mathrm{~km}$ by $64 \mathrm{~km}$ region centred on the Fella River basin (Fig. 1). With the approach based on the climatological variogram, one may take into account information from all the realizations (e.g. rainfall field for successive time steps) assuming the fields to have similar statistical characteristics except for a constant factor. The variogram can therefore be normalised by the respective variance of each field considered and then averaged over all the realizations. Assuming the structure functions have the same shape, the mean normalised variogram obtained (with variance parameter equal to one), also called climatological variogram, is representative of all the realizations. In particular, we have used here a spherical variogram as a reference spatial structure.
The main adjustment factor of this function is the variogram shape and particularly its range (i.e., the decorrelation distance). This allowed us to calibrate a relation between the rainfall accumulation time step $\Delta t$ (hours) and the range $D_{R}$ (km) (Fig. 3a), as follows:

$D_{R}=23.3 \Delta t^{0.23}$

Interestingly, this equation is relatively close to the one reported by Berne et al. (2004) for flash flood events observed in France. According to Eq. (1), the range of the variogram of half-hourly rain rates is set equal to $19.5 \mathrm{~km}$.

Space and time generation of runoff is controlled mainly by the spatial distribution of the intense rainfall cells. We characterise this spatial distribution by using the concept of the indicator variogram (Barancourt et al., 1992), i.e. by converting the rainfall field into a corresponding binary process. For this, a binary function denoted $i(x, y)$, called the indicator function by Journel (1983), is defined by

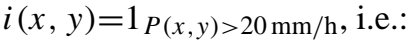

$i(x, y)=1$ if $P(x, y)>20 \mathrm{~mm} / \mathrm{h}$

$i(x, y)=0$ otherwise.

The threshold of $20 \mathrm{~mm} \mathrm{~h}^{-1}$ was selected here to isolate the fraction of the basin hit by flood producing rainfall. We analysed the binary field by using the indicator variogram, which show a significant anisotropy with longer correlations in the N55E direction. To account for anisotropy, we conceptualised the range in space as an elliptical field, quantified by the major and minor axes at each time step. We describe the temporal evolution of the spatial structure of rainfall accumulated at 30-min time step by reporting the time series of max and min lengths (Fig. 3c). The indicator variogram analyses highlight the high variability of the storm properties with time. During the period of very intense rainfall occurrence (i.e., between 14:00 and 18:00 CET) the major axis length ranges between 7 and $18 \mathrm{~km}$, whereas the minor axis length ranges between 3 and $5 \mathrm{~km}$. This indicates that the shape of the high intense areas is elongated, with the minor axis length equal to $30 \%$ of that of the major axis, and points out to the high spatial variability of the high intensity rainfall fields.

\section{Analyses of flood response}

Hydrologic response on the Fella River basin is examined by using a simple spatially distributed hydrologic model (KLEM - Kinematic Local Excess Model; Borga et al., 2007). The distributed model is based on availability of raster information of the landscape topography and of the soil and vegetation properties. In the model, the SCS-Curve Number (SCS-CN) procedure (US Department of Agriculture, 1986) is applied on a grid-by-grid way for the spatially distributed 
representation of runoff generating processes. A linear transfer function based on a simple description of the drainage system response is used to represent runoff propagation.

The general SCS-CN runoff equation is

$$
\begin{array}{ll}
q=\frac{\left(P-I_{a}\right)^{2}}{\left(P-I_{a}+S\right)} & \text { for } P \geq I_{a} \\
q=0 & \text { for } P<I_{a}
\end{array}
$$

where $q(\mathrm{~mm})$ is the direct runoff depth, $P(\mathrm{~mm})$ is the event rainfall depth, $I_{a}(\mathrm{~mm})$ is an "initial abstraction" or event rainfall required for the initiation of runoff, and $S(\mathrm{~mm})$ is a site storage index defined as the maximum possible difference between $P$ and $q$ as $P \rightarrow \infty . P-I_{a}$ is also called "effective rainfall", or $P_{e}$. The SCS-CN method can be applied by specifying a single parameter called the curve number, $C N$, which is function of the hydrologic soil-cover complex and ranges in principles from 1 to 100. The value of $S$ for a given soil is related to the curve number as

$S=C\left(\frac{100}{C N}-1\right)$

where $C$ is a calibration parameter $(\mathrm{mm})$, called infiltration storativity. The use of the parameter $C$ allows one to use the spatial distribution of $C N$ values, which represents an input data in this work, and to simulate correctly, at the same time, the observed flood water balance (Borga et al., 2007).

The distributed runoff propagation procedure is based on the identification of drainage paths, and requires the characterization of hillslope paths and channeled paths. We used a channelization support area $\left(A_{s}\right)\left(\mathrm{km}^{2}\right)$, which is considered constant at the subbasin scale, to distinguish hillslope elements from channel elements and two parameters $\left(v_{h}\right.$ and $\left.v_{c}\left(\mathrm{~m} \mathrm{~s}^{-1}\right)\right)$ as the two time-invariant hillslope and channel velocities, respectively. The model has been implemented at 30-min time step and using a 20 -m grid size cell for the description of landscape morphology and soil properties.

The hydrological model used here is based on the rather strong assumption that space-time excess rainfall distribution and drainage network structure provide the most important controls on extreme flood response. However, its parsimonious structure is a favourable characteristics for analysis of flash flood events, which are affected by considerable uncertainty on rainfall and discharge data. As such, this model structure has been used in a number of studies on flash flood events (Zhang et al., 2001; Borga et al., 2007). The accuracy of the model simulations have been examined and discussed by Borga et al. (2007), who showed that the model reproduces peak discharge and the time of peak discharge reasonably well. The model parameters calibrated at 1-km rainfall aggregation length were used for the sensitivity analysis.

\subsection{Analysis of space-time precipitation variability at three catchment scales and at two rainfall resolu- tions}

To characterize the influence of temporal and spatial variability of rainfall on flood response according to the metric provided by the flow distance concept, we utilized 30-min rainfall fields at two different aggregation lengths to compute the following quantities:

1. the mean rainfall rate over the catchment at time $t$ during the storm, $M(t)$;

2. the fractional coverage of the basin by rainfall rates exceeding $20 \mathrm{~mm} \mathrm{~h}^{-1}, F(t)$;

3. the normalized time-distance of rainfall from the basin outlet, $D(t)$; and

4. the normalised dispersion of rainfall, $S_{\mathrm{NOR}}(t)$.

Consistently with analyses reported above, the threshold of $20 \mathrm{~mm} \mathrm{~h}^{-1}$ was selected here to isolate the fraction of the basin hit by flood producing rainfall. The mean rainfall rate and fractional coverage time series provide basic information on rainfall mass balance and distribution of rainfall rates over the catchment. They do not provide information on the spatial distribution of rainfall relative to the basin network structure, however. The drainage network, as represented by the routing time $\tau(u)$ from the arbitrary location $u=x, y$ to the outlet of the basin. The routing time $\tau(u)$ is defined as

$\tau(u)=\frac{L_{h}(u)}{v_{h}}+\frac{L_{c}(u)}{v_{c}}$

where $L_{h}(u)$ is the distance from the generic point $u$ to the channel network following the steepest descent path, $L_{c}(u)$ is the length of the subsequent drainage path through streams down to the watershed outlet, and $v_{h}$ and $v_{c}$ are the two invariant hillslope and channel velocities introduced above. The routing time provides a natural metric for analyzing the spatial distribution of rainfall, as shown previously by Woods and Sivapalan (1999), Zhang et al. (2001) and Borga et al. (2007). The routing time incorporates both geometric and kinematic properties in its determination.

The normalized time-distance at time $t, D(t)$, is a function of the rainfall field $R(t, u)$ and the routing time $\tau(u)$. It is defined as the ratio of the rainfall-weighted centroid routing time $D_{1}(t)$ and the mean routing time $D_{\text {mean }}$,

$D(t)=\frac{D_{1}(t)}{D_{\text {mean }}}$

In Eq. (5) the time-distance $D_{1}(t)$ is given by

$D_{1}(t)=|A|^{-1} \int_{A} w(t, u) \tau(u) d u$

where $A$ is the spatial domain of the drainage basin and the weight function $w(t, u)$ is given by

$w(t, u)=\frac{R(t, u)}{|A|^{-1} \int_{A} R(t, u) d u}$ 


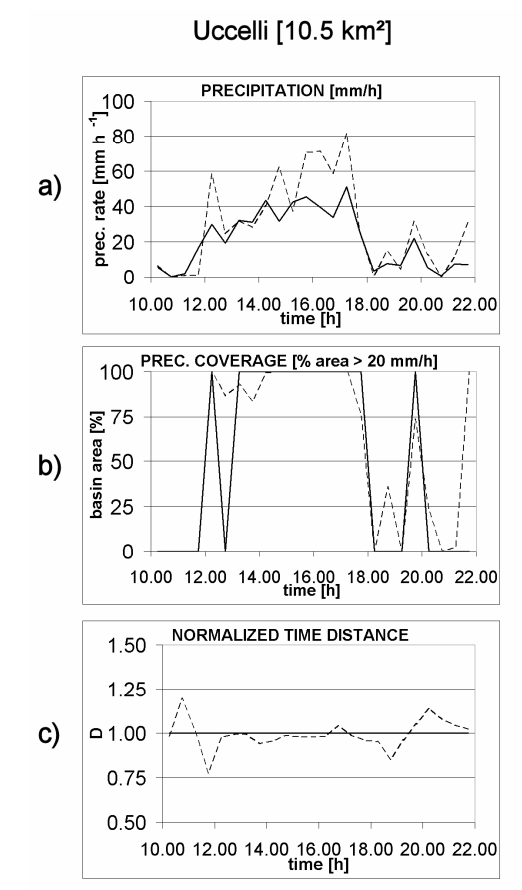

Fella at S.Caterina $\left[139.0 \mathrm{~km}^{2}\right]$
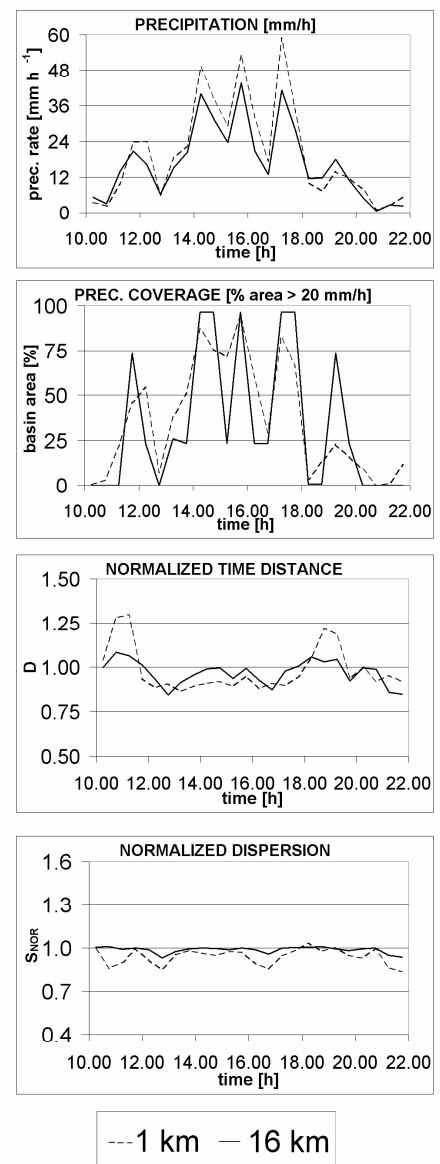

Fella at Moggio Udinese $\left[623.0 \mathrm{~km}^{2}\right]$
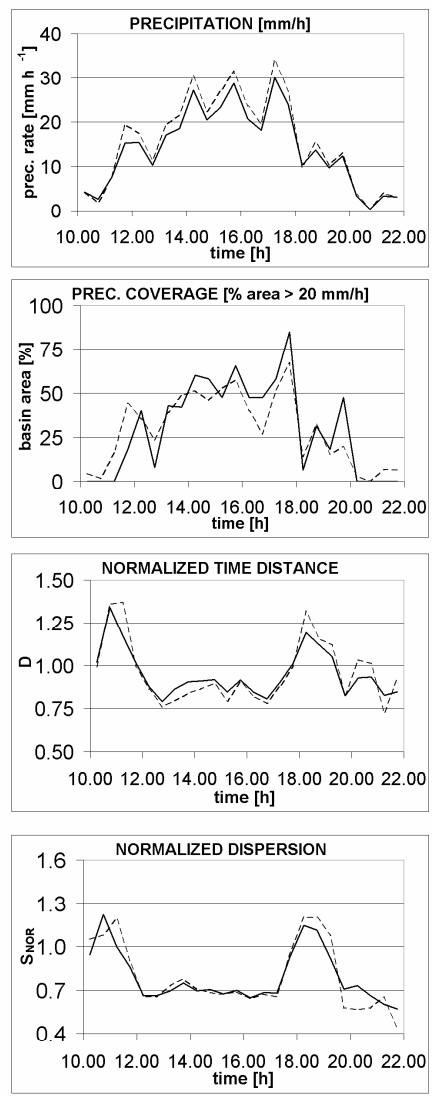

d)

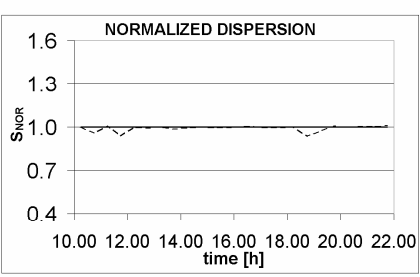

Fig. 4. Precipitation analysis for three catchments (Uccelli at Pontebba, $10.5 \mathrm{~km}^{2}$, Fella at S. Caterina, $139 \mathrm{~km}^{2}$ and Fella at Moggio Udinese, $\left.623 \mathrm{~km}^{2}\right)$, with two different rainfall grid resolutions ( $1 \mathrm{~km}$ and $\left.16 \mathrm{~km}\right)$ :

(a) mean rainfall intensity $\left[\mathrm{mm} \mathrm{h}^{-1}\right]$; (b) coverage (for precipitation intensity $>20 \mathrm{~mm} \mathrm{~h}^{-1}$ ); (c) normalized time distance; (d) normalized time dispersion.

The value $D_{\text {mean }}$ is defined as

$D_{\text {mean }}=|A|^{-1} \int_{A} \tau(u) d u$

Values of $D(t)$ close to 1 reflect a rainfall distribution either concentrated close to the mean time-distance or homogeneous, with values less than one indicating that rainfall is distributed near the basin outlet, and values greater than one indicating that rainfall is distributed towards the periphery of the drainage basin.

The rainfall-weighted flow time-distance dispersion is given by:

$S(t)=\left\{\int_{A} w(t, u)\left[\tau(u)-D_{1}(t)\right]^{2} d u\right\}^{0.5}$
The dispersion for uniform rainfall is defined by:

$S_{1}=\left\{\int_{A}\left[\tau(u)-D_{\text {mean }}\right]^{2} d u\right\}^{0.5}$

and the normalised dispersion is given by

$S_{\mathrm{NOR}}(t)=\frac{S(t)}{S_{1}}$

Values of $S_{\mathrm{NOR}}(\mathrm{t})$ close to 1 reflect a uniform-like rainfall distribution, with values less than 1 indicating that rainfall is characterised by a unimodal peak, and values greater than 1 indicating cases of multimodal rainfall peaks close and far from the basin outlet.

Results are reported in Fig. 4 for three catchments: Rio degli Uccelli $\left(10.5 \mathrm{~km}^{2}\right)$, Fella at S. Caterina $\left(139.0 \mathrm{~km}^{2}\right)$ and Fella at Moggio $\left(623.0 \mathrm{~km}^{2}\right)$ and for rainfall fields aggregated over length scales of 1 and $16 \mathrm{~km}$. Rio degli Uccelli 
and Fella at Moggio represent the smallest and largest catchment examined in the study, respectively, whereas Fella at S. Caterina represents an intermediate catchment scale. Inspection of the mean rainfall intensity shows that aggregation at 16-km scale has relatively less effects over the larger basin (Fella at Moggio), whereas significant smoothing effects (with reductions up to 50\%) are recognised over Rio degli Uccelli, particularly for the period 14:00 to 18:00, with intermediate effects for Fella at S. Caterina.

The dynamics of the fractional coverage is consistent with the information provided by the temporal evolution of the rainfall spatial structure reported in Fig. 3c. For Rio degli Uccelli, which was located under one of the major convection band during the phase of explosive growth of the storm, the size of the rainfall band is enough to ensure full coverage in the period between 14:00 and 17:30. Interestingly, increasing the rainfall aggregation length induces generally a sharper behaviour in the rainfall coverage, as it is illustrated by the case of the Fella at S. Caterina. Inspection of this last case shows that, even though the ratio of rainfall resolution to the characteristic basin length $\left(L_{r} / L_{w}\right)$ is larger than one for the $16-\mathrm{km}$ resolution, the rainfall is far from being spatially uniform, being the catchment located between two or more rainfall cells. This needs to be accounted for in the discussion below.

Examination of normalised distance highlights different behaviours across the various catchments. Analysis of normalised dispersion over the period of heavy rainfall and at $1-\mathrm{km}$ resolution shows that rainfall concentration translates from the lower portion of the basin to the upper portion and that the dynamics of the normalised distance increases with catchment scale, as expected. Aggregation over 16-km length scale has generally the effect to reduce the dynamics of the normalised distance and has a different impact according to catchment scale. For Rio degli Uccelli, aggregation over 16-km averages out any dynamics, as expected since the rainfall field provided to the catchment at this resolution is completely uniform.

A similar pattern can be recognised for the normalised dispersion, with precipitation exhibiting a unimodal peak for Moggio (at least during the period of extreme precipitation) and a more uniform distribution for the case of Rio degli Uccelli, with S. Caterina being in an intermediate position.

\section{Influence of rainfall spatial aggregation on peak dis- charge simulation}

Effects of rainfall spatial aggregation on flood response modelling are examined here with reference to the ratio of rainfall resolution to the characteristic basin length $\left(L_{r} / L_{w}\right)$, taken as the square root of the watershed area. To elucidate the controls of rainfall aggregation on model error, the KLEM model was applied over ten different subbasins ranging from $10.5 \mathrm{~km}^{2}$ to $623 \mathrm{~km}^{2}$ (Table 1 and Fig. 2) and by using four
Table 1. Characteristics of the study basins, with catchment area and mean areal cumulated precipitation at four different rainfall resolutions; basin id numbers as reported in Fig. 2.

\begin{tabular}{llllll}
\hline Basin id number & Area $\left[\mathrm{km}^{2}\right]$ & \multicolumn{4}{c}{$\begin{array}{c}\text { Mean areal precipitation } \\
{[\mathrm{mm}]}\end{array}$} \\
\cline { 3 - 6 } & & $1 \mathrm{~km}$ & $4 \mathrm{~km}$ & $8 \mathrm{~km}$ & $16 \mathrm{~km}$ \\
\hline 1 & 10.5 & 353 & 327 & 314 & 255 \\
2 & 17.5 & 307 & 303 & 307 & 246 \\
3 & 24 & 287 & 279 & 285 & 192 \\
4 & 50 & 301 & 284 & 229 & 160 \\
5 & 71.2 & 246 & 240 & 240 & 222 \\
6 & 139 & 241 & 237 & 235 & 203 \\
7 & 165 & 247 & 244 & 239 & 211 \\
8 & 250 & 253 & 248 & 244 & 216 \\
9 & 329 & 237 & 235 & 232 & 224 \\
10 & 623 & 189 & 187 & 183 & 170 \\
\hline
\end{tabular}

different rainfall resolutions: 1-, 4-, 8- and 16-km. This provides 40 different combinations of watershed characteristic lengths and rainfall aggregations.

As shown above, varying the spatial rainfall resolution induces rainfall volume errors, a reduction of the rainfall apparent spatial variability and a distortion of the rainfall geometry with respect to the flow distance metric. In order to separately address the first two effects we performed numerical experiments in which rainfall depths are rescaled and forced to be exactly preserved at each time step over the range of rainfall resolutions and catchment scales examined.

The error analysis was carried out for rainfall and runoff volumes and for peak discharges, by comparing results obtained by using a given input resolution with those obtained from 1-km grid size, considered here as the reference resolution. The error statistics "normalised rainfall volume error" $\varepsilon_{r}$, "normalised runoff volume error" $\varepsilon_{v}$ and "normalised peak discharge error" $\varepsilon_{q}$ were computed for rainfall volume, runoff volume and peak discharge, respectively, as follows:

$\varepsilon_{r}=\frac{\left|P_{L r}-P_{1}\right|}{P_{1}}$,
$\varepsilon_{v}=\frac{\left|V_{L r}-V_{1}\right|}{V_{1}}$,
$\varepsilon_{q}=\frac{\left|Q_{L r}-Q_{1}\right|}{Q_{1}}$,

where $P_{L r}$ and $P_{1}, V_{L r}$ and $V_{1}$, and $Q p_{L r}$ and $Q p_{1}$, represent the rainfall volume, the runoff volume and the peak discharge resulting from aggregation over $L_{r}$ - and 1-km length, respectively. The error statistics were computed before and after rescaling the rainfall fields at different resolution to preserve rainfall volumes.

Examination of the normalised rainfall volume errors (Fig. 5a) highlights the impact of the error caused by incorrectly smoothing the rainfall volume either into or out of the watershed; this generally corresponds to negative errors - i.e. underestimation of the true rainfall volumes (Table 1). These results generalise those reported at the previous 


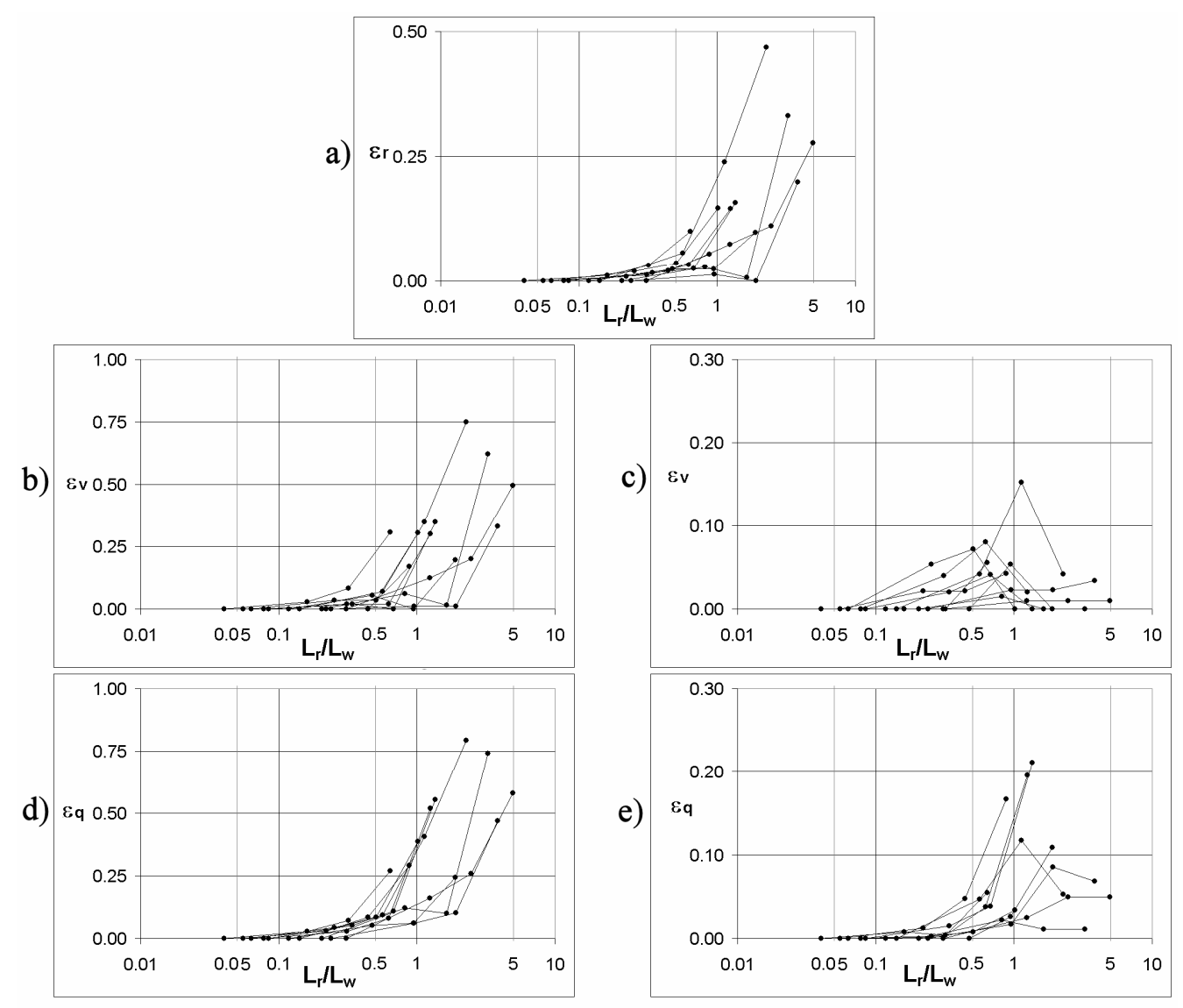

Fig. 5. Relationship between the ratio $L_{r} / L_{w}$ and (a) normalised rainfall error; (b) normalised runoff volume error before rainfall volume rescaling; (c) normalised runoff volume error after rainfall volume rescaling; (d) normalised peak discharge error before rainfall volume rescaling; (e) normalised peak discharge error after rainfall volume rescaling.

Section for the catchments of Rio degli Uccelli and Fella at Moggio and examined by using grid resolutions equal to 1 and $16 \mathrm{~km}$. A large rainfall volume error was found for grid size equal to $16 \mathrm{~km}$ for the Rio degli Uccelli. This corresponds to $L_{r} / L_{w}$ equal to 5.1, for which the normalised rainfall volume error amounts to $27 \%$. On the contrary, the error for the Fella basin at Moggio, for which $L_{r} / L_{w}$ is equal to 0.64 , amounts to $9 \%$. For the Fella at S. Caterina $\left(L_{r} / L_{w=1.37)}\right.$, the error amounts to $15 \%$. The figure shows that use of the ratio $L_{r} / L_{w}$ is capable to filter out quite effectively the effect of the catchment size on the rainfall volume error. Inspection of the maximum values of the errors shows that the error is up to 0.1 for $L_{r} / L_{w}$ equal to 0.4 , and then increases to 0.2 for $L_{r} / L_{w}$ equal to 1.0 and to 0.5 for $L_{r} / L_{w}$ equal to 2.5 .

Results are reported in Fig. 5b, c, d and e for the volume and peak errors, respectively. Large runoff volume errors are shown in Fig. 5b, particularly for the 2005 event, which is characterised by a peak value around 0.75 for a value of $L_{R} / L_{W}$ slightly exceeding two. The figure shows that the general pattern of rainfall volume errors is transmitted to the volume errors and that the rainfall volume errors generally magnify through the rainfall-runoff modelling, as it is expected after examining the structure of the SCS-CN runoff model.

The impact of reduced rainfall variability alone on runoff volume errors is illustrated by Fig. 5c, where errors are reported after rainfall volume rescaling. The figure shows that errors are sharply reduced, and generally below $10 \%$. For one case (Aupa at Moggio) the runoff volume error slightly exceeds 0.15 .

The relationship between the normalised peak discharge error and $L_{r} / L_{w}$, before rainfall volume rescaling, is reported in Fig. 5d. The pattern of peak discharge errors reported in this figure is consistent with that of runoff volume errors, as expected. The error may reach values up to 0.75 for $L_{r} / L_{w}$ slightly exceeding two. Peak discharge errors after rainfall volume rescaling are reported in Fig. 5e. This figure reveals that runoff volume errors explains the peak discharge errors in a number of cases, but not always. In three cases the peak discharge errors are comprised between 0.15 and 0.22 , and are not related to the corresponding volume 
errors, which are less than 0.05 . Inspection of the simulated hydrographs for these cases (not reported here for the sake of brevity) indicates that errors are related to differences in the peak timing. This observation indicates that increasing the rainfall aggregation length produces, in some cases, a large distortion of the rainfall spatial distribution with respect to the river network, hence resulting in considerable errors in the shape of the simulated hydrographs (including peak values and timing). This is not unexpected, because errors in the representation of the concentration of rainfall distribution in terms of flow distance translate into a distorted timing distribution of the simulated runoff.

\section{Summary and conclusions}

This paper focuses on the analysis of the effects of spatial rainfall resolution on runoff simulation for an extreme flash flood event. The increasing availability of radar observations at different spatial resolutions requires examination of the impact of using different aggregation lengths on hydrologic modelling, with specific focus on highly variable flash flood-generating storms. Focus on extreme flash flood events leads, by necessity, to an event-based and opportunistic approach, as opposed to driven by observations from carefully designed field campaigns in experimental watersheds. Extreme, flood-producing storms are spatially and temporally rare and are seldom represented in the observations from experimental watersheds. Accurate post event analyses played an essential role in providing the data required for the present study.

Our evaluations are based on combining fine space-time rainfall observations with a distributed hydrologic modeling based on an empirical infiltration model and a network-based representation of hillslope and channel flow. Radar observations and model analyses are used to evaluate the sensitivity of model results to spatial aggregation of rainfall at various catchment scales ranging from $10.5 \mathrm{~km}^{2}$ to $623 \mathrm{~km}^{2}$. Four rainfall spatial resolutions are considered, with grid size equal to 1-, 4-, 8- and 16-km. A dimensionless parameter given by the ratio between length resolution and the square root of the watershed area $\left(L_{r} / L_{w}\right)$ is used to describe the sensitivity of runoff model.

The analyses are focused on sensitivity of the simulated peak discharges to three different issues: i) rainfall spatial resolution; ii) rainfall volume errors and biased rainfall spatial variability; iii) distortion of rainfall spatial variability with respect to the river network. The principal conclusions of the study are summarized below.

1. Increasing the $L_{r} / L_{w}$ parameter induces large errors on the simulated peak discharge. Maximum values of the peak discharge error are up to 0.2 for $L_{r} / L_{w}$ equal to 0.5 and to 0.33 for $L_{r} / L_{w}$ equal to 1.0 . The error may reach values up to 0.75 for $L_{r} / L_{w}$ exceeding 2.0. All these errors are negative - i.e. the simulated peak discharge decreases by increasing the $L_{r} / L_{w}$ parameter.

2. An important error source related to spatial rainfall aggregation is the rainfall volume error caused by incorrectly "smoothing rainfall volume" either into or out of the watershed. For $L_{r} / L_{w}<1.0$, around $50 \%$ of the peak discharge error is due to the rainfall volume error. The remaining error is significantly controlled by the interaction between the attenuated and geometrically biased rainfall spatial variability and the smoothing effects of catchment characteristics.

3. We examined the role of river network geometry in the averaging of space-time rainfall and on simulated peak discharges after rescaling the rainfall fields to preserve rainfall volumes. Increasing the resolution length may lead to a distorted geometry of the rainfall field with respect to the river network. This is an important control on peak discharge error - when rainfall volumes are preserved.

Further work might determine whether the results obtained in this investigation apply to other model formulations. The present investigation has obtained illustrative examples of how rainfall variability, as filtered by using different spatial aggregation lengths, feeds through to variability in modelled runoff response at the catchment scale. More extensive investigations would strengthen this understanding and provide additional guidance on the design of radar/raingauge networks for flow forecasting and the spatial resolution requirements for rainfall at different catchment scales.

Acknowledgements. The writers wish to thank three anonymous reviewers for the discussions and insight provided. This work was supported by the European Community's Sixth Framework Programme through the grant to the budget of the Integrated Project FLOODsite, Contract GOCE-CT-2004-505420 and in part by the STREP Project HYDRATE, Contract GOCE 037024. The Regional Meteorological Observatory of Friuli-Venezia-Giulia is thanked for making the radar dataset available and for the assistance in data analysis.

Edited by: G. Roth

Reviewed by: L. Marchi and two anonymous Referees

\section{References}

Andréassian V., Perrin, C., Michel, C., Usart-Sanchez, I., and Lavabre, J.: Impact of imperfect rainfall knowledge on the efficiency and the parameters of watershed models, J. Hydrol., 250, 206-223, 2001.

Barancourt, C., Creutin, J. D., and Rivoirard, J.: A Method for Delineating and Estimating Rainfall Fields, Water Resour. Res., 28, 1133-1144, 1992.

Bell, V. A. and Moore, R. J.: The sensitivity of catchment runoff models to rainfall data at different spatial scales, Hydrol. Earth 
Syst. Sci., 4, 653-667, 2000,

http://www.hydrol-earth-syst-sci.net/4/653/2000/.

Berne, A., Delrieu, G., Creutin, J. D., and Obled, C.: Temporal and spatial resolution of rainfall measurements required for urban hydrology, J. Hydrol., 299, 166-179, 2004.

Blöschl G. and Sivapalan, M.: Scale issues in hydrological modelling: a review, Hydrol. Process., 9, 251-290 1995.

Borga, M., Tonelli, F., Moore, R. J., and Andrieu, H.: Long-term assessment of bias adjustment in radar rainfall estimation, Water Resour. Res., 38, 1226, doi:10.1029/2001WR000555, 2002.

Borga, M., Boscolo, P., Zanon, F., and Sangati, M.: Hydrometeorological analysis of the August 29, 2003 flash flood in the eastern Italian Alps, J. Hydrometeorol., 8, 1049-1067, 2007.

Borga, M., Gaume, E., Creutin, J. D., and Marchi, L.: Surveying flash flood response: gauging the ungauged extremes, Hydrol. Process., 22(18), 3883-3885, 2008.

Creutin, J. D. and Borga, M.: Radar hydrology modifies the monitoring of flash flood hazard, Hydrol. Process., 17(7), 1453-1456, 2003.

Journel, A. G.: Non parametric estimation of spatial distributions, Math. Geol., 15, 445-467, 1983.

Kouwen, N. and Garland, G.: Resolution considerations in using radar rainfall ata for flood forecasting, Can. J. Civ. Eng., 16, 279289, 1989.

Lebel, T., Bastin, G., Obled, C., and Creutin, J.: On the Accuracy of Areal Rainfall Estimation: A Case Study, Water Resour. Res., 23, 2123-2134, 1987.

Naden P. S.: Spatial variability in flood estimation for large catchments: the exploitation of channel network structure, Hydrol. Sci. J., 37, 53-71, 1992.

Nicotina, L., Alessi-Celegon, E., Rinaldo, A., and Marani, M.: On the impact of rainfall patterns on the hydrologic response, Water Resour. Res., 44, W12401, doi:10.1029/2007WR006654, 2008.

Norbiato, D., Borga, M., Sangati, M., and Zanon, F.: Regional Frequency Analysis of Extreme Precipitation in the eastern Italian Alps and the August 29, 2003 Flash Flood, J. Hydrol., 345(3-4), 149-166, 2007.
Norbiato, D., Borga, M., Degli Esposti, S., Gaume, E., and Anquetin, S.: Flash flood warning based on rainfall depth-duration thresholds and soil moisture conditions: An assessment for gauged and ungauged basins, J. Hydrol., 362(3-4), 274-290, doi:10.1016/j.jhydrol.2008.08.023., 2008.

Obled, C., Wendling, J., and Beven, K.: Sensitivity of hydrological models to spatial rainfall patterns: An evaluation using observed data, J. Hydrol., 159, 305-333, 1994.

Ogden, F. L. and Julien, P. Y.: Runoff model sensitivity to radar rainfall resolution, J. Hydrol., 158, 1-18, 1994.

Segond, M. L., Wheater, H. S., and Onof, C.: The significance of spatial rainfall representation for flood runoff estimation: A numerical evaluation based on the Lee catchment, UK, J. Hydrol., 347, 116-131, 2007.

Smith, M. B., Seo, D. J., Koren, V. I., Reed, S. M., Zhang, Z., Duan, Q., Moreda, F., and Cong, S.: The distributed model intercomparison project (DMIP): motivation and experiment design, J. Hydrol., 298, 4-26, 2004.

US Department of Agriculture: Urban hydrology for small watersheds, US Department of Agriculture Tech. Release, 55, 164 pp., 1986.

Winchell, M., Gupta, H., and Sorooshian, S.: On the Simulation of Infiltration- and Saturation-Excess Runoff Using Radar-Based Rainfall Estimates: Effects of Algorithm Uncertainty and Pixel Aggregation, Water Resour. Res., 34, 2655-2670, 1998.

Woods, R. A. and Sivapalan, M.: A synthesis of space-time variability in storm response: Rainfall, runoff generation and routing, Water Resour. Res., 35, 2469-2485, 1999.

Zhang, Y., Smith, J. A., and Baeck, M. L.: The hydrology and hydrometeorology of extreme floods in the Great Plains of eastern Nebraska, Adv. Water Resour., 24, 1037-1050, 2001. 